Universidad y Salud

ARTÍCULO DE REVISIÓN

\title{
Multirresistencia bacteriana: Reto terapéutico en trasplante renal
}

\author{
Bacterial multiresistance: Therapeutic challenge in renal transplantation
}

Geraldíne Gallego-Maldonado'1 orcid.org/0000-0002-1954-6367

Aura Shirley Otálora-Díaz' orcid.org/0000-0002-8199-2077

Eliana Ximena Urbano-Cáceres ${ }^{*}$ orcid.org/0000-0001-7218-7300

Carol Mayerline Morales-Súarez' orcid.org/0000-0003-2602-1988

1 Universidad de Boyacá. Tunja, Colombia

Fecha de recepción: Noviembre 22 - 2017

Fecha de revisión: Julio 6 - 2018

Fecha de aceptación: Diciembre 11 - 2018

Gallego-Maldonado G, Otálora-Díaz AS, Urbano-Cáceres EX, Morales-Súarez CM. Multirresistencia bacteriana: Reto terapéutico en trasplante renal. Univ. Salud. 2019;21(1):72-87. DOI: http://dx.doi.org/10.22267/rus.192101.141

\section{Resumen}

Introducción: Se estima que el 86\% de los pacientes receptores de un trasplante renal presentan una infección por microorganismos multirresistentes, principalmente de vías urinarias (IVU) en el postrasplante, lo cual se asocia a un mal pronóstico del injerto y del paciente. Objetivo: Describir los principales mecanismos de resistencia que se encuentran en la colonización de las vías urinarias, luego de ser sometido un paciente a un trasplante renal y algunos factores de riesgo que aumentan la probabilidad de complicaciones de este postoperatorio. Materiales y métodos: Se realizó una revisión de la literatura en bases de datos como Medline, Embase y Science Direct, empleando palabras claves validadas entre los años 2007 a 2017. Resultados: Los factores de riesgo asociados a la adquisición de IVU luego de un trasplante renal son sexo femenino, diabetes mellitus, anomalías de la vía urinaria e instrumentación de la uretra, los microorganismos asociados al trasplante renal son SARM (Staphylococcus aureus resistente a Meticilina) en un 20\% en salas de nefrología y Escherichia coli y Klebsiella pneumoniae tipo BLEE en un 30\% y 28\%. Conclusiones: Los mecanismos de resistencia de mayor prevalencia en trasplantes son causados por bacterias productoras de BLEE, asociados a la profilaxis postrasplante que se realiza.

Palabras clave: Trasplante de riñón; infecciones urinarias; infecciones bacterianas; factores de riesgo; farmacorresistencia microbiana; profilaxis antibiótica. (Fuente: DeCS, Bireme).

\begin{abstract}
Introduction: It is estimated that $86 \%$ of patients receiving a renal transplant have an infection by multiresistant microorganisms, mainly urinary tract (UTI) in post-transplant, which is associated with poor prognosis of the graft and patient. Objective: To describe the main mechanisms of resistance found in the colonization of the urinary tract from a patient after being submitted to a renal transplant and some risk factors that increase the likelihood of complications of this postoperative. Materials and methods: A review of literature in databases such as Medline, Embase and Science Direct was conducted, using key words validated from 2007 to 2017. Results: The risk factors associated with the acquisition of UTI after a renal transplant are female sex, diabetes mellitus, urinary tract anomalies and instrumentation of the urethra. The microorganisms associated with renal transplantation are MRSA (Methicillin-resistant Staphylococcus aureus) in 20\% in rooms of nephrology and Escherichia coli and Klebsiella pneumoniae type ESBL in 30\% and 28\% respectively. Conclusions: The mechanisms of resistance of higher prevalence in transplants are caused by bacteria producing ESBL, associated with the post-transplant prophylaxis performed.
\end{abstract}

Key words: Kidney transplantation; urinary tract infections; bacterial infections; risk factors; drug resistance, microbial; antibiotic prophylaxis. (Source: DeCS, Bireme).

\footnotetext{
*Autor de correspondencia

Eliana Ximena Urbano-Cáceres

e-mail: eliurbano@uniboyaca.edu.co
} 


\section{Introducción}

El trasplante de riñón es el tratamiento de elección para la etapa final de la enfermedad renal (ESRD por sus siglas en inglés), sin embargo, según Ojo et al., en 2012 más del 80\% de los pacientes con ESRD son tratados con diálisis de mantenimiento debido a la escasez de órganos para un trasplante efectivo por las discrepancias entre la demanda y el suministro de órganos y otros factores como ser mayor de 35 años, raza negra, o comorbilidades como insuficiencia cardiaca o enfermedades psiquiátricas $^{(1)}$. El trasplante renal se asocia generalmente con la mortalidad y la morbilidad disminuida así como una mejor calidad de vida en pacientes con $\operatorname{ESRD}^{(2)}$; sin embargo, el notable progreso en el procedimiento quirúrgico y la inmunosupresión después del trasplante renal, la infección de las vías urinarias (IVU) siguen siendo un problema importante en estos pacientes(3), la IVU es una de las complicaciones infecciosas más frecuente, que se presenta hasta en un $86 \%$ de los casos trasplantados según un estudio realizado en Irán por Shams et al., en el Hospital de Trasplante de Órganos Montaseriey en 2017, considerándose como el factor de riesgo más importante para el debilitamiento de la función del injerto( ${ }^{(4)}$.

Las infecciones del tracto urinario son las infecciones más frecuentes en el paciente sometido a trasplante renal; su presentación clínica es variable encontrándose desde pacientes con bacteriuria asintomática a otros con cuadros clínicos de gravedad que comprometen su pronóstico. Las infecciones urinarias sintomáticas pueden localizarse en el tracto urinario inferior presentando los síntomas como disuria, polaquiuria, dolor suprapúbico e incluso hematuria. La infección en el tracto urinario superior se presenta como pielonefritis del injerto, cuadro de mayor gravedad. La clínica se presenta con escalofríos, dolor en la localización del injerto renal y hematuria por lo que este cuadro deberá diferenciarse de los episodios de rechazo agudo del injerto(5).

Las secuelas graves de una IVU incluyen recurrencia frecuente, pielonefritis con sepsis, daño renal en niños pequeños, parto prematuro y complicaciones de uso frecuente de antimicrobianos, incluyendo resistencia a antibióticos de alto nivel y colitis por Clostridium difficile y Escherichia coli, esta última considerada como el uropatógeno causante de la mayoría de IVU, pero patógenos menos comunes tales como Enterococcus faecalis y otros Enterococos que frecuentemente se aprovechan de un tracto urinario anormal o cateterizado para causar infecciones oportunistas(6)(4).

Esta revisión de literatura tiene como objetivo describir los principales mecanismos de resistencia que se encuentran en la colonización de las vías urinarias luego de ser sometido un paciente a un trasplante renal y algunos factores de riesgo que aumentan la probabilidad de complicaciones de este postoperatorio.

\section{Materiales y métodos}

Se llevó a cabo una revisión bibliográfica, para la búsqueda se emplearon palabras clave como trasplante de riñón, infecciones urinarias, infecciones bacterianas, factores de riesgo, farmacorresistencia microbiana y profilaxis antibiótica, previamente validadas en el DeCS (Descriptores en Ciencias de la Salud) y $\mathrm{MeSH}$ (Medical Subject Headings), las bases de datos consultadas fueron: Medline, Embase, Lilacs, ScienceDirect, Scopus, SciELO y The Cochrane Library.

Se usaron las palabras clave en diferentes combinaciones para obtener resultado acorde a la investigación propuesta, se utilizó criterios de inclusión como: artículos científicos a nivel mundial publicados entre 2007 y 2017 y como criterios de exclusión, artículos sobre resistencia bacteriana sin relación con trasplante renal. De acuerdo a lo anterior, se obtuvo un total de 64 artículos de los cuales 33 fueron en inglés y 31 en español, al momento de aplicar los criterios de exclusión, se descartaron 9 artículos, para un total de 55. 


\section{Resultados y discusión}

\section{Infecciones de vías urinarias en trasplante renal}

Las infecciones en los pacientes trasplantados siguen un esquema de presentación acorde con el momento después del trasplante, las infecciones precoces (dentro del primer mes postrasplante) son fundamentalmente asociadas a patógenos nosocomiales, problemas quirúrgicos $\mathrm{y}$ en ocasiones derivadas del donante; las infecciones por gérmenes oportunistas ocurren más tardíamente, entre el primer $y$ el sexto mes postrasplante, coincidiendo con el periodo de máxima inmunosupresión. Por último, las infecciones tardías (a partir del 6o mes) pueden ser secundarias a microorganismos comunitarios $\mathrm{u}$ oportunistas en función del grado de inmunosupresión del receptor(5).

La infección de vías urinarias (IVU) se define como la colonización, invasión y multiplicación en la vía urinaria, de microorganismos patógenos, especialmente bacterias(7) la sospecha de infección se sustenta en el cuadro clínico y el análisis de orina y se confirma con el sedimento urinario como la presencia de $>5$ leucocitos por campo (40x) en orina centrifugada, que equivalen a un recuento de $>20$ leucocitos $/ \mathrm{mm} 3$ y en el urocultivo En pacientes asintomáticos: en mujeres: $>10^{5}$ colonias $/ \mathrm{ml}$, en hombres: $>10^{4}$ colonias $/ \mathrm{ml}$, denominado como Bacteriuria Asintomática. En pacientes sintomáticos la presencia de más de $10^{3}$ colonias $/ \mathrm{ml}$ se considera significativa y debe instaurarse tratamiento antibiótico ${ }^{(8)}$.

Así se convierte en la complicación infecciosa más común en los pacientes a los que se le realiza un trasplante de órgano sólidos puesto que son pacientes sometidos a una inmunosupresión con fármacos para evitar el rechazo del órgano, según Bodro et al., en 2015 a nivel mundial alcanza una prevalencia del 45$72 \%$ para todas las infecciones, se observa que las tasas de incidencia de infecciones como cistitis y pielonefritis en pacientes con trasplante de riñón, inicia en los primeros 3-6 meses después del trasplante( ${ }^{(9)}$. Las infecciones bacterianas que muy a menudo son causadas por bacterias multirresistentes como $E$. coli, aunque se ha documentado que patógenos menos comunes como Gram positivos (Staphylococcus aureus), pueden alcanzar el tracto urinario causando infecciones oportunistas( ${ }^{(6)}$ y secuelas graves como la disminución en la sobrevida del injerto hasta la sepsis.

En pacientes con trasplante renal, aumenta la inmunodeficiencia a través del uso de medicamentos inmunosupresores ${ }^{(10)}$, que expresa un fracaso en los mecanismos inmunológicos frente a agentes biológicos de naturaleza diversa, presentándose complicaciones y aumento de la estancia a pesar de los avances en las técnicas quirúrgicas y el desarrollo de terapias profilácticas eficaces, continúan siendo una frecuente causa de morbimortalidad en el periodo pos trasplante. El paciente se somete a tratamientos invasivos, anestesia general con intubación endotraqueal, cirugía vascular de alto riesgo, drenajes, cateterismo venoso central, uretral y vesical, así como a múltiples punciones arteriales y venosas, que en conjunto favorecen la adquisición, multiplicación y desarrollo de microorganismos, principalmente bacterias de origen hospitalario tales como tales como Staphylococcus aureus, Pseudomonas aeruginosa, Acinetobacter sp, Enterobacteriaceae y Enterococcus sp; cuyo patrón de resistencia a los antibióticos puede presentar variaciones importantes entre los diferentes centros y como consecuencia, la aparición de sepsis grave y resistencia a los antimicrobianos a causa del uso de antibióticos para la profilaxis inicial del paciente(11).

\section{Trasplante renal}

El trasplante de órgano, es un tratamiento médico complejo que permite que órganos, tejidos o células de una persona puedan reemplazar los mismos en personas enfermas ya sea para mejorar su calidad de vida o para evitar su muerte. El primer trasplante renal registrado con éxito fue realizado en Boston en 1947, una joven en coma profundo de 10 días por uremia y anuria tras shock séptico a causa de un aborto complicado(12). Para los casos de trasplante de riñón por insuficiencia renal terminal, las causas 
más frecuentes de esta patología son las malformaciones congénitas en niños, complicación de la hipertensión arterial, la diabetes mellitus o los diversos tipos de glomerulonefritis en adultos(12).

Los mecanismos que intervienen en el alorreconocimiento y en los elementos de la respuesta inmunitaria son esenciales para la consolidación del trasplante renal; además, la identificación de los factores de riesgo y su prevención desde etapas precoces, pueden influir en el aumento de la sobrevida y la disminución de la mortalidad de los pacientes con insuficiencia renal crónica terminal que requieren trasplante renal(13,14), el pronóstico de la intervención depende de factores que se explican a continuación:

Protocolo general del trasplante. Requiere de pruebas de laboratorio para el receptor y el donante que incluyen; para el receptor inicialmente valoración pre-trasplante con serologías para Hepatitis B, Hepatitis C, Virus de Inmunodeficiencia Humana (VIH)(15), Citomegalovirus (CMV), Virus de Epstein Barr (VEB), Chagas, pruebas no treponémicas (RPR), y prueba de tuberculina; se debe tener en cuenta que la infección crónica por hepatitis B, hepatitis C y VIH son contraindicación para la realización del trasplante( ${ }^{(8)}$. En cuanto, a donantes vivos y cadavéricos se les realiza serología para hepatitis B (antígeno de superficie, Anticore totales e IgM), VIH, hepatitis C, Virus Epstein Barr (VEB), Citomegalovirus (CMV), Toxoplasma gondii, Virus Linfotrópico de células T Humanas Tipo I y II (HTLV I y II), Chagas y RPR(16).

Contraindicaciones. Pueden clasificarse en absolutas y relativas; dentro de las absolutas se encuentran, la neoplasia maligna reciente con actividad metastásica, infección activa, enfermedad extrarrenal irreversible sin rehabilitación o con expectativas de vida inferior a un año, enfermedad psiquiátrica con pérdida de autonomía o competencia, incumplimiento terapéutico reiterado, adicción a drogas y/o alcohol sin posibilidades de rehabilitación y prueba cruzada positiva IgG frente a células T del donante(17). En las contraindicaciones relativas, que pueden ser clínicamente valoradas están, la edad avanzada > de 75 años, enfermedad cardiovascular, hepatopatía crónica avanzada, anomalías de vías urinarias, tumores malignos previos y alguna enfermedad de base que complique el procedimiento(17).

Selección del donante. Depende de si este es vivo o muerto, en el caso de un trasplante renal (TR) de donante vivo, una vez comprobado que el candidato es apto para el trasplante se debe valorar si existe en el entorno familiar opciones para el TR principalmente si el paciente es joven. Si hay más de un posible donante vivo se deben valorar las características de éste: edad, riesgo, diferencia de edad y de masa corporal entre donante y receptor, y el grado de compatibilidad ABO y Antígenos Leucocitarios Humanos (HLA). Este será sometido a un protocolo de estudio o evaluación rigurosa por etapas, empezando con los exámenes generales y la prueba cruzada, y otros como la arteriografía, angioTAC o angioRMN. Es necesario esclarecer la posibilidad de una contraindicación como disminución en el aclaramiento de creatinina, proteinuria y/o hematuria, hipertensión arterial, diabetes, obesidad y antecedentes de cáncer, litiasis o hepatitis para no continuar con los estudios(16).

Si el receptor no dispone de la opción de un posible donante vivo será incluido en lista de espera de trasplante cadavérico y la selección se realizará habitualmente atendiendo al grado de compatibilidad ABO y HLA. En el trasplante renal cadavérico se debe revisar aspectos como, edad, diferencia de índice de masa corporal entre donante y receptor, tiempo en lista de espera de trasplante y grado de sensibilización; los factores que más influyen en la supervivencia del injerto son el grado de compatibilidad HLA, la isquemia fría y la función renal retardada del injerto, el tipo de inmunosupresión, la incidencia de rechazo agudo y el realizar el trasplante en situación de pre-diálisis(16).

Las infecciones en receptores de trasplante renal constituyen una de las tres primeras causas de muerte; su diagnóstico y su tratamiento pueden ser muy complejos debido a la inmunosupresión a la que están sometidos, las acciones 
encaminadas a su prevención son muy relevantes y pretenden reducir el impacto clínico, económico y social(18).

Profilaxis del trasplante renal. El TR es un procedimiento susceptible de contaminación debido a la manipulación de la vejiga, la cual es expuesta para realizar la anastomosis ureterovesical, ésta se encuentra previamente infectada como resultado de orina residual estancada, es por esto, que los pacientes que reciben un TR deben tener una profilaxis prequirúrgica, que, según López et al., $y$ otros autores ${ }^{(9,7,19)}$ se realiza con cefazolina e ivermectina administradas de acuerdo al protocolo de cada institución. Según Lee et al.(19), los pacientes que recibirán un trasplante también reciben valganciclovir $o$ aciclovir durante 6 meses para la profilaxis de Citomegalovirus (CMV) y trimetoprimsulfametoxazol para Pneumocystis jiroveci desde la segunda semana, hasta el tercer mes postrasplante(20). El tratamiento inmunosupresor postrasplante es necesario para evitar el rechazo del órgano y produce una mayor predisposición a la infección. De hecho, la intensidad del tratamiento inmunosupresor es un factor de riesgo fundamental en el desarrollo de complicaciones infecciosas ya que estas bacterias pasan a convertirse en potenciales agentes infecciosos; la intensidad y la duración de la terapia inmunosupresora es la clave en la frecuencia y en el tipo de las complicaciones infecciosas ${ }^{(21)}$.

Alberú et al.(18), han demostrado en su estudio titulado "Prevención de las infecciones en el receptor de trasplante renal: recomendaciones de un grupo de expertos" que las IVU son uno de los factores más influyentes a largo plazo de la función renal para un paciente pos trasplantado, así mismo, un análisis del registro americano United States Renal Data System (USRDS) muestra que las infecciones de más de 6 meses después del trasplante renal son asociadas una mayor mortalidad y perdida del injerto(19). Es por ello que las infecciones del tracto urinario en los primeros 4 a 6 meses del trasplante deberían ser asociados a pielonefritis y bacteriemia, siendo este período caracterizado por la presencia de reinfecciones a pesar de un tratamiento estándar de 10-14 días, incluso con una vía urinaria normal(7).

Factores de riesgo predisponentes para adquirir una IVU postrasplante. El riesgo de invasión bacteriana ha sido asociado a múltiples factores como sexo femenino por la cercanía del meato urinario, comorbilidades como diabetes mellitus por la inmunosupresión y anomalías de la vía urinaria e instrumentación de la uretra por la facilidad de adquirir un microorganismo patógeno(10); las causas de nefropatía se asocian en mayor medida con que el donante sea cadavérico, la mayor duración en diálisis pre trasplante, las serologías positivas pre trasplante para Hepatitis B (HBV), Hepatitis C (HCV), CMV haploidéntico (HLA), además de la presencia de un catéter doble $\mathrm{J}$ o stent urinario, asociado también a los medicamentos inmunosupresores y a los episodios de rechazo como fuentes de complicaciones médico-quirúrgicas(22). En otras circunstancias, como infecciones con requerimiento de manejo intrahospitalario, el lupus eritematoso sistémico, el antecedente de cáncer, el trasplante renal previo, la historia de terapia anti rechazo y la albúmina sérica basal < $3,5 \mathrm{mg} / \mathrm{dL}^{(23)}$, también se muestran como factores de riesgo asociados a complicaciones postrasplante, que el donante cadavérico presente una presión arterial media < $70 \mathrm{mmHg}(19)$; factor predisponente para adquirir una IVU(24) y como factores protectores se encuentra ser de sexo masculino, edad menor a 50 años y la ausencia de comorbilidades ${ }^{(25) .}$

Antes de 1980, el $60 \%$ de los pacientes que recibieron un TR tenía al menos un episodio infeccioso grave durante el primer año, dicha tasa ha disminuido significativamente en los últimos años(2), aunque las infecciones son una causa frecuente de morbi-mortalidad en los pacientes receptores de un trasplante renal, su prevención y tratamiento adecuado son pilares sobre los que debe asentarse un programa de trasplante de calidad. El correcto tratamiento de las infecciones en el receptor de un trasplante se ve dificultado por la toxicidad y las interacciones entre los fármacos antimicrobianos y los inmunosupresores, así como, por la escasa tolerancia de estos pacientes a ciertos 
procedimientos agresivos necesarios para establecer un diagnóstico de certeza(5). Las complicaciones infecciosas continúan siendo una importante amenaza en la buena evolución del injerto, donde los microorganismos responsables de estos episodios pueden ser endógenos del receptor, procedentes del injerto, procedentes del medio externo (comunitario) o adquiridos a nivel intrahospitalario(24).

Epidemiología en el trasplante renal. A nivel internacional, España sigue siendo líder mundial en trasplante de órganos, en cifras, en el 2010 se realizaron 3.773 trasplantes, frente a 4.028 que se efectuaron en 2009, la menor mortalidad entre jóvenes implica que se eleva la edad media del donante a 56,5 años. El tiempo de espera en el riñón es el más largo entre 20 y 24 meses. Desde marzo 2010, la Organización Nacional de Trasplantes (ONT) ha anunciado la preparación de la donación de órganos en España a través de la figura anglosajona del «buen samaritano», es decir, un voluntario que ofrece un riñón a un desconocido de forma altruista, se destaca 22 personas, 12 hombres y 10 mujeres, con edades comprendidas entre los 19 y los 63 años, quienes iniciaron una donación en cadena, en total, el número de donantes se ha incrementado en un $1,8 \%$, lo que ha permitido aumentar los trasplantes en un 2,1\%, con máximos históricos en riñón (2.328) y pulmón (219). En 2010 la modalidad de donante vivo alcanzó los 240 trasplantes renales, que representan un $10,7 \%$ del total(26).

Mediante el programa Resistencia Zero propuesto en España, el Centro Europeo para la Prevención y el Control de Enfermedades se estima que en la Unión Europea (UE) aproximadamente 400.000 pacientes/año sufren una infección causada por una de las bacterias multirresistentes más comunes, y unos 25.000 pacientes/año mueren como consecuencia de una infección causada por este grupo de microorganismos, además, los costos que generan se aproximan a los 1.500 millones

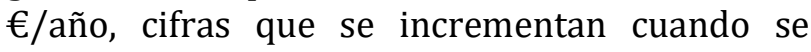
suma pacientes inmunosuprimidos por un trasplante renal con una IVU por un microorganismo resistente, por esto se han planteado distintas estrategias con el fin de combatir la aparición y diseminación de la resistencia antimicrobiana(27).

El trasplante de riñón en donante vivo (LDKT por sus siglas en inglés) representa un tercio de los trasplantes realizados en Estados Unidos y continúa ofreciendo resultados superiores en comparación con la diálisis de mantenimiento y el trasplante de riñón de donante fallecido para individuos con insuficiencia renal terminal(28), el número anual de donantes vivos de riñón. En Estados Unidos se alcanzó un pico máximo de 6.647 en 2004. La década anterior vio un aumento del $120 \%$ en la donación de riñón vivo. Sin embargo, desde 2004, sin embargo, la donación de riñón vivo disminuyó en un 13\% de 2004 a 2011(29). Los candidatos afroamericanos e hispanos representan una proporción significativa de la lista de espera nacional para trasplantes de riñón, el número (17.184) y la proporción $(55,5 \%)$ de los receptores de trasplante caucásicos disminuyeron ligeramente en 2015 en comparación con el año anterior(30)

Cada año en México se realizan 5.925 trasplantes, siendo la mayoría de éstos los de córnea (3.025), riñón (2.707), hígado (149) y corazón (44), en un Hospital de México entre enero de 2008 a diciembre de 2012, se realizaron 35 trasplantes renales, $54 \%$ en hombres, el promedio de edad fue de 50 años, el $71 \%$ de los pacientes eran hipertensos, la causa de la insuficiencia renal crónica (IRC) más frecuente fue diabetes mellitus en $34 \%$, el promedio de años con IRC fue de 3,5 años, a 51\% de los pacientes se les realizó el trasplante de donador vivo relacionado, el $8,5 \%$ de donador vivo no relacionado, el $40 \%$ de donador cadavérico y el promedio de días de hospitalización fue de 9,8 días por paciente, dentro de las complicaciones se encontraron infecciones postrasplante, necrosis tubular aguda y sangrado post trasplante(15).

En Ecuador según estadísticas, actualmente se encuentran 6.000 pacientes con diagnóstico de insuficiencia renal crónica (IRC) que están sometidos a terapia dialítica, el $97 \%$ de ellos por hemodiálisis; el $66 \%$ pertenecen al sistema de 
salud beneficiario representando anualmente un gasto de 50 millones de dólares que constituyen un enorme gasto en salud, puesto que la mayoría de los centros que ofrecen procedimientos de hemodiálisis están en el sector privado. Así los trasplantes se convierten en una respuesta eficiente y equitativa que mejora la calidad de vida de los pacientes con IRC y reduce el gasto para cualquier el de salud porque el costo de un trasplante se compensa con el costo de un año de diálisis, pero esto se complica cuando los pacientes con trasplante renal presentan con IVU(31).

En Colombia se realizan 961 trasplantes de órganos al año, con una tasa de 20,4/1'000.000 habitantes, de estos el 70,1\% corresponden a trasplante renal (tasa 14,7/1'000.000 habitantes)(7), al comparar el número de trasplantes realizados por trimestres durante el año 2013, se evidencia que en el cuarto trimestre (octubre - diciembre), se realizó el mayor número de trasplantes (258), correspondiente al el 26,8\%; por su parte el trimestre que reportó menos procedimientos fue el tercero con un $23,1 \%$ del total para el año. Durante el año 2013 el $46 \%$ de los trasplantes renales se realizaron en cuatro IPS del país, el porcentaje restante fueron realizados en las demás IPS habilitadas para prestar servicios de trasplante(32).

El total de trasplantes de riñón en Colombia realizados en el año 2013 (691, incluyendo trasplantes combinados), representa una tasa de trasplante de riñón por millón de población de 14,7 (DANE, población proyectada 2013: 47'121.089), a el 31 de diciembre del año 2013, se realizaron 587 (85\%) trasplantes renales con órganos de donantes cadavéricos incluyendo los trasplantes combinados, que representa una tasa de trasplante de riñón de donante cadavérico de 12,5 y 105 (15\%) con riñones de donantes vivos, equivalente a una tasa de trasplante de riñón con donante vivo de 2,2. En el año 2013 con respecto al año 2012, se presentó un aumento del 18\% en los trasplantes de riñón con donante vivo, mientras que los trasplantes con donante cadavérico disminuyeron un $15,3 \%{ }^{(7)}$.

\section{Resistencia bacteriana}

Actualmente representa un serio problema de salud global, esta puede variar según países y/o áreas geográficas, reportándose que el mayor porcentaje de resistencia antibiótica corresponde a bacterias gram negativas(33). En América Latina para el 2017 fue de 45\%, seguido de Europa con 39\%, en menor proporción EE.UU y Canadá, con $8 \%$ y $5 \%$, respectivamente(34). La multirresistencia representa un reto terapéutico que deja pocas posibilidades para el tratamiento de las Infecciones del Tracto Urinario (ITU) en pacientes renales puesto que los mecanismos que utilizan las bacterias para defenderse de los antibióticos están en constante evolución(34). (Tabla 1).

En el mecanismo de modificación enzimática al antibiótico, los genes que codifican estas enzimas pueden ser intrínsecas o adquiridas $y$ encontrarse en el cromosoma bacteriano o en plásmidos, lo cual permite su fácil transferencia entre diferentes bacterias(21). La clasificación de modificación enzimática del antibiótico por medio de las ß-lactamasas (Tabla 2).

Tabla 1. Principales mecanismos de resistencia

\begin{tabular}{ll}
\hline \multicolumn{1}{c}{$\begin{array}{c}\text { Mecanismo de } \\
\text { resistencia }\end{array}$} & \multicolumn{1}{c}{ Modo de acción } \\
\hline \multirow{3}{*}{ Transducción } & $\begin{array}{l}\text { Transferencia de cualquier parte de un genoma bacteriano, cuando un fago atemperado (genoma del } \\
\text { virus que se encuentra inserto en el ADN bacteriano) durante su fase de ensamblaje, encapsula este } \\
\text { material. Si el fragmento de ADN que queda envuelto es totalmente bacteriano se denomina } \\
\text { transducción generalizada y si sólo se encapsula parte del genoma bacteriano pero se conserva el } \\
\text { genoma viral se habla de transducción especializada(35). }\end{array}$ \\
\hline \multirow{2}{*}{ Conjugación } & $\begin{array}{l}\text { Transferencia de material genético contenido en plásmidos de una bacteria a otra a través de una hebra } \\
\text { sexual; estos plásmidos usualmente contienen genes que le confieren resistencia a drogas, antisépticos y } \\
\text { desinfectantes }(36) .\end{array}$ \\
\hline \multirow{2}{*}{ Transformación } & Transferencia de genes desde un ADN desnudo de una bacteria previamente lisada a otra que lo recibe y \\
& lo incorpora a su genoma(37). \\
\hline
\end{tabular}


Movimiento de una sección de ADN (transposon) que puede contener genes para la resistencia a Transposición diferentes antibióticos y otros genes casete unidos en equipo para expresión de un promotor en particular(38).

Bombas de salida o Operan tomando el antibiótico del espacio periplásmico y expulsándolo al exterior, con lo cual evitan bombas eflujo que llegue a su sitio de acción(39).

Cambios en la permeabilidad de la membrana externa

Las bacterias generan cambios de la bicapa lipídica, siendo la membrana alterada, principalmente, por cambios en las porinas. Estas son proteínas con estructura barril $\beta$ formadas por láminas $\beta$, pertenecen a las proteínas integrales de membrana, que son las que se ubican a través de una membrana celular y funcionan como poros a través de los cuales las moléculas se pueden difundir y regulan la entrada de algunos elementos, entre ellos, los antibióticos(39).

Alteraciones del sitio de acción

Son mecanismos de mutación que se dan al azar donde el genotipo y el fenotipo de las proteínas es decir el sitio específico donde va a actuar el antimicrobiano genera una mutación, teniendo como resultado que el antibiótico no se puede unir a la bacteria e interrumpir una función vital de ésta. Este mecanismo es, principalmente, utilizado por las bacterias Gram positivas, las cuales generan cambios estructurales en los sitios de acción de los antibióticos ß-lactámicos a nivel de las proteínas unidoras de penicilinas(40).

Las bacterias expresan enzimas capaces de crear cambios en la estructura del antibiótico haciendo que éste pierda su funcionalidad(21). Las ß-lactamasas son las más prevalentes como mecanismos de resistencia expresado por las bacterias, éstas son proteínas capaces de hidrolizar el anillo ß-lactámico

Modificación enzimática del que poseen los antibióticos de esta familia. Los antibióticos ß-lactámicos son bacteriolíticos, y actúan inhibiendo la síntesis de la barrera de peptidoglicanos de la pared celular de bacterias sensibles. La antibiótico barrera de peptidoglicanos es importante para la integridad estructural de la pared celular, especialmente para los microorganismos Gram positivos. Los genes que codifican estas enzimas pueden encontrarse en el cromosoma bacteriano o en plásmidos, lo que permite su fácil transferencia entre diferentes bacterias, representando un gran reto para el control de las infecciones(39).

\section{Mecanismos de resistencia a grupos de antibióticos}

El fenotipo de resistencia a la meticilina (y a la oxacilina) es mucho más frecuente entre las diferentes especies de Gram positivos con excepción de Staphylococcus lugdunensis y Staphylococcus saprophyticus,

Resistencia a la meticilina

(Oxacilina)

Resistencia a los macrólidos y a la Clindamicina que en $S$. aureus. Esta resistencia se debe a la adquisición del gen mecA el cual es un gen que se encuentra en las células bacterianas y que permite que una bacteria sea resistente a los antibióticos como la meticilina, la penicilina y otros antibióticos similares a la penicilina que codifica la proteína fijadora de penicilina (PBP) PBP2a, que posee baja afinidad por los betalactámicos. La resistencia a la meticilina implica resistencia a todos los betalactámicos, incluyendo penicilinas, combinaciones de betalactámico con inhibidor de betalactamasa, cefalosporinas, monobactamas y carbapenemas(40).

Los macrólidos, junto con las lincosamidas y las estreptograminas B (MLSB) son tres grupos de antimicrobianos de estructuras químicas diferentes, pero con mecanismos de acción similares. En los estafilococos, la resistencia a los macrólidos (eritromicina, claritromicina, azitromicina, midecamicina) puede asociarse a diferentes fenotipos de sensibilidad o de resistencia a las lincosamidas (clindamicina) que se pueden identificar en el laboratorio mediante el método de difusión con discos de eritromicina y clindamicina o mediante dilución en caldo utilizando una combinación de ambos antimicrobianos(40).

La resistencia a estos antibióticos es frecuente en $S$. aureus. El mecanismo de resistencia más habitual en cepas de $S$. aureus es el mediado por los genes de metilasa de resistencia a la eritromicina (erm) los cuales codifican metilasas y confieren resistencia a macrólidos, lincosamidas y estreptograminas del grupo B. Los genes más frecuentemente detectados en esta especie son erm(A) y erm(C), seguidos por el gen $\operatorname{erm}(\mathrm{B})^{(41)}$.

Los dos fenotipos más frecuentes de resistencia a los aminoglucósidos que se pueden encontrar al realizar las pruebas de sensibilidad in vitro son el de resistencia a la gentamicina y a la tobramicina pero sensibilidad aparente a la amikacina y el de sensibilidad a la gentamicina y resistencia a la tobramicina y a la amikacina(40).

Resistencia a los aminoglucósidos
En bacterias como S. aureus la resistencia a estos antibióticos se produce principalmente por la acción de enzimas codificadas por los genes $\operatorname{aac}\left(6^{\prime}\right)$-Ie-aph(2') - -Ia, $\operatorname{ant}\left(4^{\prime}\right)$-Ia, $\operatorname{aph}(3)$-IIIa y $\operatorname{ant}(6)$-Ia, $\operatorname{ant}\left(3^{\prime}\right)$-Ia y str. Estos se han detectado vehiculizados por plásmidos y transposones, favoreciendo su diseminación entre bacterias. A nivel clínico, el gen ant(4')-Ia es el más prevalente debido a la alta frecuencia del clon CC5-t067(41). 
Tabla 2. Clasificación de las ß-lactamasas

\begin{tabular}{|c|c|}
\hline ß-lactamasas & Mecanismo de acción \\
\hline $\begin{array}{l}\text { ß-lactamasas tipo } \\
\text { AmpC }\end{array}$ & $\begin{array}{l}\text { Estas enzimas se han encontrado codificadas por cromosomas en una amplia variedad de bacterias } \\
\text { Gram negativas; algunas de ellas son fáciles de recordar utilizando la nemotecnia AMPCES } \\
\text { (Aeromonas spp., Morganella morganii, Providencia spp., Pseudomonas aeruginosa, Proteus spp. (indol } \\
\text { positivo), Citrobacter freundii, Enterobacter spp. y Serratia spp.). Estas hidrolizan generalmente a las } \\
\text { cefalosporinas de espectro reducido, cefalosporinas de tercera generación, aztreonam e inhibidores } \\
\text { de ß-lactamasas. Las bacterias con AmpC cromosómico bajo condiciones normales, producen esta } \\
\text { enzima en bajas cantidades sin alterar significativamente la sensibilidad a las cefalosporinas de } \\
\text { tercera generación(34). }\end{array}$ \\
\hline $\begin{array}{l}\text { B-lactamasas de } \\
\text { espectro extendido } \\
\text { (BLEE) }\end{array}$ & $\begin{array}{l}\text { Han sido reportadas en múltiples especies de bacterias Gram negativas, Klebsiella spp. y Escherichia } \\
\text { coli son los gérmenes más frecuentemente implicados. Estas enzimas confieren resistencia a las } \\
\text { oximinocefalosporinas (como las cefalosporinas de tercera generación), el aztreonam, las penicilinas } \\
\text { y las cefalosporinas de espectro reducido. Por el contrario, son incapaces de hidrolizar cefamicinas } \\
\text { (cefoxitina y cefotetán) y carbapenem. Las BLEE son inhibidas por los inhibidores de ß-lactamasas } \\
\text { como el ácido clavulánico, el sulbactam y el tazobactam, lo cual las diferencia de las ß-lactamasas tipo } \\
\text { AmpC. La mayoría de BLEE se ha originado por medio de mutaciones espontáneas de ß-lactamasas de } \\
\text { espectro reducido, por cambios en los aminoácidos en su sitio activo, lo que permite ampliar su } \\
\text { capacidad hidrolítica(34). }\end{array}$ \\
\hline Carbapenemasas & $\begin{array}{l}\text { Este grupo de enzimas hidroliza hasta los carbapenémicos, pueden estar codificadas en el cromosoma } \\
\text { bacteriano o estar presentes en elementos genéticos móviles. Se ha propuesto una clasificación en dos } \\
\text { grupos: carbapenemasas de serina y metalo-ß-lactamasas, denominadas así por la dependencia de } \\
\text { metales como el zinc para su funcionamiento(34). }\end{array}$ \\
\hline $\begin{array}{l}\text { Otras enzimas } \\
\text { modificadoras }\end{array}$ & $\begin{array}{l}\text { Existen otras enzimas responsables de la aparición de resistencia contra los antimicrobianos, como } \\
\text { son las metilasas, acetil-transferasas, nucleotidiltransferasas y fosfotransferasas que inactivan, } \\
\text { especialmente, los aminoglucósidos. De este grupo, vale la pena mencionar a la acetil-transferasa AAC } \\
\left(6^{\prime}\right) \text {-Ib y a las } 16 \mathrm{~S} \text { rARN metilasas las cuales confieren resistencia a varios aminoglucósidos, inclusive } \\
\text { kanamicina, amikacina y tobramicina( }{ }^{(34)} \text {. }\end{array}$ \\
\hline
\end{tabular}

Mecanismos de resistencia a los antibióticos en bacterias Gram negativas(34) Principales mecanismos de resistencia en el
trasplante renal. En 2012, Medina et al., publicaron un artículo en el que se estima que $14 \%$ de los pacientes receptores de un trasplante renal presentan una infección por microorganismos multirresistentes en el postrasplante durante el primer mes, incluyendo bacterias Gram negativas entéricas y no fermentadoras, lo cual se asocia a un mal pronóstico del injerto y del paciente. Aquí evidencian que los mecanismos de resistencia de mayor prevalencia en los trasplantes son causados por bacterias productoras de BLEE(33). El hallazgo de bacterias multirresistentes dentro del primer mes postrasplante podría deberse a las maniobras invasivas realizadas en el ámbito hospitalario(33). En un estudio posterior de Espinar et al., en 2015, las IVU afectan entre el $5 \%$ y el $36 \%$ de los pacientes con trasplante renal, siendo la principal complicación infecciosa en la población de pacientes y una de las causas más comunes de pérdida de injerto y mortalidad, como se ha visto en el este porcentaje puede variar entre un rango de 5 a $86 \%(42)$, y coincide en que las BLEE son un gran problema en cuanto a resistencia bacteriana en IVU postrasplante renal ya que son un grupo de enzimas que rápidamente confieren resistencia a penicilinas, cefalosporinas de primera, segunda y tercera generación y aztreonam(41).

En un estudio retrospectivo de casos y controles realizado en el año 2015, que tuvo como objetivo identificar los factores de riesgo independientes para IVU en pacientes con trasplante renal no hospitalizados asociada a E. coli productora de BLEE y $K$ pneumoniae productora de carbapenemasas, se compararon datos clínicos y parámetros de la función renal durante los episodios de IVU, recurrencia de la IVU y la tasa de recaída, así como la caracterización molecular de los aislamientos y el respectivo perfil de susceptibilidad antimicrobiana y la profilaxis antibiótica previa, concluyendo que la función 
retardada del injerto, la comorbilidad por diabetes mellitus, la previa exposición a antibióticos, la profilaxis antibiótica y la IVU recurrente son factores de riesgo independientes para adquirir infecciones por E. coli productora de BLEE y $K$. pneumoniae. Además, mediante estudios de epidemiología molecular demostraron que blaCTX-M era el gen codificador de BLEE más común, y a alta corresistencia a otros antibióticos (no- $\beta$ lactámicos) que se encuentran en las bacterias productoras de BLEE en la IVU de pacientes con trasplante renal(43).

En México en el año 2010 se realizó el "Estudio prospectivo de la vigilancia de la infección de las vías urinarias después del trasplante renal" que tuvo como objetivo establecer la frecuencia de IVU en pacientes trasplantados de riñón y evaluar los mayores factores de riesgo para el desarrollo de IVU, en donde los patógenos aislados de mayor prevalencia fueron $E$. coli (31,5\%), Candida albicans $(21,0 \%)$ y Enterococcus spp. (10,5\%), seguidas de $P$. aeruginosa, K. pneumoniae, Morganella morganii, Enterobacter cloacae y Micrococcus spp. Las infecciones secundarias se produjeron por Enterococcus spp. (57\%), E. coli (28\%) y Micrococcus spp. $(14,2 \%)$, la resistencia a los antibióticos fue del $22 \%$ para la ciprofloxacina y del 33\% para la ampicilina, la vigilancia de la ITU durante los primeros 3 meses es una buena opción para mejorar la calidad de vida de los pacientes con trasplante renal, la salida de la función del injerto y los antibiogramas proporcionaron una buena alternativa terapéutica a los pacientes que presentaron IVU después de recibir un aloinjerto de riñón, además, declara que la resistencia a los antibióticos es un problema clínico frecuente debido al uso imprudente de estos medicamentos en la profilaxis inicial(20).

El control de la resistencia antimicrobiana, forma parte importante de la vigilancia antibiótica tal como lo recomienda la Organización Mundial de la Salud (OMS); debido a que principalmente se origina al uso indiscriminado de los antibióticos. Así es que se presentan fenotipos de resistencia cruzada hacia otros antimicrobianos de la misma clase, o con el mismo mecanismo de acción e incluso de otras familias. A pesar de dicho control, se hace necesario estudiar más a fondo los aspectos medioambientales y genéticos más importantes en la generación de fenotipos multirresistentes de bacterias adquiridas por pacientes postrasplante, los cuales tienen menos capacidad de defensa en cuanto a la respuesta inmunológica(40).

\section{Principales microorganismos colonizadores} en el trasplante renal. Las infecciones oportunistas (virales, fúngicas, nocardiales y protozoario) son casi inexistentes en el primer mes tras el trasplante. Las principales causas de infección son heridas bacterianas, pulmonares, urinarias e intravenosas, e infecciones relacionadas con el catéter que se observan en los pacientes después de cualquier procedimiento quirúrgico(22). Según Samanipaur los microorganismos Gram-positivos, principalmente $S$. aureus y $S$. epidermidis ( $S$. epidermidis), causan aproximadamente el $70 \%$ de las infecciones relacionadas a catéter, $S$. aureus es la principal causa de infecciones del torrente sanguíneo y la consiguiente morbilidad y mortalidad entre los pacientes en hemodiálisis, el tipo más común de $S$. aureus en las salas de nefrología es resistente a meticilina (SARM)(44), lo cual sugiere que la aparición de SARM dentro de la comunidad se ha convertido en un importante problema de salud pública, las prácticas de atención en salud, afectando cada vez más la población(45).

Entre los microorganismos Gram negativos principalmente identificados en las IVU postrasplante renal se encuentra $E$. coli y $K$. pneumoniae productoras de BLEE que son las principales enterobacterias causantes de infecciones intrahospitalarias(21) según Medina en Uruguay se encuentra seguido Enterococcus spp y Acinetobacter baumannii en las siguientes proporciones (Tabla 3)(46). 
Tabla 3. Principales microorganismos encontrados en las IVU de pacientes con trasplante renal

\begin{tabular}{|c|c|c|}
\hline Microorganismos Gram positivos & Asociado a: & $\begin{array}{l}\text { Porcentaje de prevalencia } \\
\text { (Ubicación, Año) }\end{array}$ \\
\hline Staphylococcus aureus ${ }^{(45)}$ & Catéter/sonda vesical & 18 (EE.UU 2008) \\
\hline Staphylococcus epidermidis(24) & Catéter/sonda vesical & 6.31 (España, 2009) \\
\hline$S A R M(21)$ & Salas de nefrología (IAAS) & 20 (Perú, 2014) \\
\hline Enterococcus faecium(25) & Contaminación & 3 (Polonia, 2014) \\
\hline Microorganismos Gram negativos & Asociado a: & Porcentaje de prevalencia \\
\hline Escherichia coli $(B L E E)^{(9)}$ & IAC & 30 (EE.UU, 2014) \\
\hline Klebsiella pneumoniae $(B L E E)^{(9)}$ & IAC & 28 (EE.UU, 2014) \\
\hline Pseudomona aeruginosa ${ }^{(10)}$ & IAAS & 11 (2015, Colombia) \\
\hline Enterococcus $(10)$ & IAAS & 10 (2015, Colombia) \\
\hline Acinetobacter baumannii(11) & IAAS & 2.7 (EE.UU, 2014) \\
\hline Enterobacter sp.(11) & IAAS & 2.7 (EE.UU, 2014) \\
\hline Citrobacter sp.(11) & IAAS & 2.1 (EE.UU, 2014) \\
\hline Serratia sp.(23) & IAAS & 0.5 (EE.UU, 2015) \\
\hline
\end{tabular}

IAC: Infecciones adquiridas en comunidad. IAAS: Infecciones asociadas a la atención en salud.

Epidemiología de la resistencia bacteriana en pacientes con TR. Con el tiempo la incidencia de complicaciones infecciosas en trasplante renal ha ido reduciendo de un $60 \%$ a $80 \%$, en los años ochenta y a un 30 a $49 \%$ a finales del siglo XX. Aunque los datos de dicha incidencia cambian según la forma de revisión de la información y la severidad de las infecciones incluidas, el comportamiento es muy similar independientemente del país evaluado ${ }^{(47) .}$

En Uruguay en el año 2012 según aportes de Medina, et al., en cuanto a la multirresistencia antibiótica, en un estudio retrospectivo realizado en el Centro de Nefrología del Hospital de Clínicas, Universidad de la República obtuvieron un grado de multirresistencia del $44,7 \%$, donde el $58,7 \%$ se desarrolló en el primer mes postrasplante a nivel hospitalario, y E. coli, fue el agente bacteriano más frecuente, ya que de los 76 episodios de infecciones comunitarias se estableció diagnóstico etiológico en 48, dentro de estos, 23 casos correspondieron a E. coli y 12 a Klebsiella spp. Por otra parte, de 62 casos de infecciones nosocomiales, en 55 se aisló microorganismo causal, 16 correspondieron a Enterococcus spp., 10 a Klebsiella spp., y 10 a Acinetobacter baumannii esta problemática es alarmante y superior a otras cifras reportadas en otros estudios, además informaron la presencia de microorganismos multirresistentes en la comunidad con el $32,6 \%$, de E. coli y Klebsiella spp $p^{(46) .}$

En Argentina en 2015, Calza et al., mediante un estudio observacional encontraron episodios de IVU inmediata, principalmente producidas por microorganismos productores de BLEE como $K$. pneumoniae, refieren que el hallazgo de esta bacteria multirresistente dentro del primer mes postrasplante se debía a las maniobras invasivas realizados en el ámbito hospitalario, y E. coli fue aislada en episodios de ITU temprana y tardía de las cuales sólo una fue productora de BLEE, siendo la sensibilidad similar a las infecciones urinarias de pacientes no trasplantados de la comunidad(10).

En España, García et al., destacó la presencia de K. pneumoniae en pacientes con trasplante renal donde las opciones de tratamiento en las infecciones causadas por estos microorganismos son limitadas, ya que presentan resistencia a cefalosporinas (excepto cefamicinas), penicilinas de amplio espectro y aztreonam. Además, con frecuencia, los plásmidos que codifican esta resistencia portan genes de resistencia a otros antibióticos, como las quinolonas, 
aminoglucósidos y cotrimoxazol, y el fenómeno de resistencia cruzada es muy frecuente dificultando la selección de un tratamiento adecuado para mejorar la capacidad del paciente para combatir la infección(8).

Según Cruz, et al., en un estudio prospectivo en Cuba la infección por Acinetobacter spp. en el siglo XXI representa una amenaza para el receptor de trasplante renal en especial las cepas de $A$. baumannii productoras de BLEE resistentes a aminoglucósidos, fluoroquinolonas y carbapenémicos, esto constituye una preocupación en pacientes con prolongación del tiempo de hospitalización y pérdida del injerto, dificultando el tratamiento de estos pacientes y la disminución de la calidad de vida(11).

Rodríguez et al., en el 2011 observaron que en Colombia los aislamientos de $S$. epidermidis resistente a oxacilina (Sep-oxa $\left.{ }^{\circledR}\right), \quad S$. aureus resistente a oxacilina (Sau-oxa ${ }^{\circledR}$ ), Enterobacter cloacae resistente a cefotaxima (Eclo-ctx ${ }^{\circledR}$ ) y Acinetobacter baumannii resistente a imipenem (Aba-imp), fueron los fenotipos de mayor frecuencia en los servicios no UCI para los tres años de estudio, E. faecium resistente a vancomicina $\left(\right.$ Efavan $\left.^{\circledR}\right) ; E$. coli resistente a ciprofloxacina $\quad\left(\mathrm{Eco} \mathrm{cip}^{\circledR}\right) ; \quad K$. pneumoniae resistente a ceftazidima (Kpn-caz ${ }^{\circledR}$, imipenem $\left(\mathrm{Kpn}^{-i m p}{ }^{\circledR}\right)$ y ciprofloxacina (Kpn-cip $\left.{ }^{\circledR}\right), \quad E$. cloacae resistente a ceftazidima $\left(\right.$ Eclo-caz $\left.^{\circledR}\right)$, cefotaxima (Eclo-ctx ${ }^{\circledR}$ ) y ciprofloxacina (Eclo$\operatorname{cip}^{\circledR}$ ) y Pseudomonas aeruginosa resistente a ciprofloxacina (Psa-cip ${ }^{\circledR}$ ) y estas tendencias señalan que la resistencia bacteriana a los antimicrobianos en el ámbito hospitalario es un fenómeno dinámico en Colombia y son evidencia de la emergencia de los fenotipos Efa-van y Kpnimp en los hospitales(48).

Así mismo, se ha demostrado que las infecciones por $K$ pneumoniae productora de carbapenemasa (KPC) son un problema de salud pública, desde 2008 las instituciones experimentan casos endémicos de infecciones por $\mathrm{KPC}^{(49)}$ y se han encontrado estudios sobre la resistencia bacteriana en mujeres embarazadas a la ampicilina. En el estudio de Ferreira, et al., el microorganismo de mayor prevalencia fue $E$. coli en un $64 \%$, seguido de K. pneumoniae en $32 \%$; en donde $E$. coli presentó resistencia a la ampicilina en un $82 \%$ y a la gentamicina en un $3 \%$, aquí concluyeron que la elección de un antibiótico para el tratamiento de la infección de vías urinarias durante el embarazo requiere un conocimiento de los gérmenes más frecuentes y su perfil de resistencia bacteriana(50).

\section{Recomendaciones}

Según las acciones adoptadas por la Organización Mundial de la Salud (OMS) puesto que los antibióticos son medicamentos utilizados para prevenir y tratar las infecciones bacterianas, la resistencia se produce cuando las bacterias sufren cambios a consecuencia del uso de estos medicamentos, esta aparece de forma natural con el tiempo, pero el uso inapropiado de los antibióticos en los humanos está acelerando rápidamente el proceso(51).

La resistencia a los antibióticos está poniendo en riesgo los logros de la medicina moderna. Sin antibióticos eficaces para prevenir y tratar las infecciones, la quimioterapia del cáncer, las intervenciones quirúrgicas como la cesárea o las prótesis de cadera, y los trasplantes de órganos se volverán mucho más peligrosos y aumentarán las estancias en el hospital, los costos médicos, la mortalidad. Por esta razón, las medidas para prevenir y controlar la propagación de la resistencia bacteriana son acciones que debe adoptar cada uno de los actores para lograr una reducción de las cifras de resistencia como las siguientes:

- La población general: Informar a la población sobre la toma de los antibióticos únicamente cuando los prescriba un profesional médico. Seguir las instrucciones de los profesionales con respecto al uso de los antibióticos en cuanto a dosis, horas de la toma y el tiempo requerido del tratamiento y prevenir las infecciones con el lavado de manos y llevando las condiciones higiénicas mínimas.

- Los profesionales de la salud: Evitar las infecciones manejando todos los instrumentos en el contacto con el paciente de forma aséptica, 
en cuanto a los médicos mantener en constante actualización para que puedan prescribir antibióticos sólo cuando sean necesarios y de acuerdo a los protocolos y las necesidades de las bacterias multirresistentes. Notificar las infecciones resistentes a los antibióticos a los equipos de vigilancia en salud pública e Informar a los pacientes sobre cómo tomar los antibióticos correctamente, la resistencia a estos fármacos y los peligros de su uso indebido(52).

\section{Conclusiones}

En la actualidad, el problema al que se enfrenta la salud pública a nivel mundial es a los múltiples mecanismos de resistencia que presentan las bacterias tanto Gram positivas como Gram negativas relacionado directamente al uso inadecuado de antibióticos para su tratamiento. Esta problemática también se observa en pacientes que han sido sometidos a un trasplante renal debido a que en el postoperatorio se utilizan medicamentos como profilaxis para evitar cualquier infección en vías urinarias o en el sitio de la incisión, además de esto, se suma que son pacientes sometidos a una gran inmunosupresión convirtiéndose en blanco fácil para la colonización de agentes oportunistas.

Este tipo de revisiones nos da iniciativa investigativa con el fin de enriquecer el desarrollo educativo y profesional, además de aportar registros actuales sobre resistencia bacteriana en trasplante renal en Colombia.

\section{Conflicto de interés}

Los autores manifiestan que no presentan conflictos de intereses.

\section{Referencias}

1. Ojo AO, Morales JM, González-Molina M, Steffick DE, Luan FL, Merion RM, et al. Comparison of the long-term outcomes of kidney transplantation: USA versus Spain. Nephrol Dial Transplant [Internet]. 2013;28(1):21320. Available from: https://academic.oup.com/ndt/article/28/1/213/182 6777

2. Plantinga L, Pastan S, Kramer M, McClellan A, Krisher J, Patzer RE. Association of U.S. dialysis facility neighborhood characteristics with facility-level kidney transplantation. Am J Nephrol [Internet].
2014;40(2):164-73. Available from: https://www.karger.com/Article/Abstract/365596

3. Ak O, Yildirim M, Kucuk HF, Gencer S, Demir T. Infections in Renal Transplant Patients: Risk Factors and Infectious Agents. Transplant Proc [Internet]. 2013;45(3):944-8. Available from: http://www.sciencedirect.com/science/article/pii/S00 41134513002698

4. Shams SF, Eidgahi ES, Lotfi Z, Khaledi A, Shakeri S, Sheikhi $M$, et al. Urinary tract infections in kidney transplant recipients 1styear after transplantation. J Res Med Sci [Internet]. 2017;22(1):14-8. Available from:

https://www.ncbi.nlm.nih.gov/pmc/articles/PMC5367 214/

5. Castón JJ, López-oliva MO, Torre-cisneros J, Castillo DEL, Enfermedades U De, Hospital I, et al. Infecciones en el trasplante renal Cronología de las infecciones postrasplante Infecciones del tracto urinario. 2010;7(Figura 1):1-20. Available from: http://www.revistanefrologia.com/es-publicacionnefrologia-articulo-infecciones-el-trasplante-renalXX342164212000090

6. O'Brien, V. P., Hannan, T. J., Nielsen, H. V., \& Hultgren SJ. Drug and Vaccine Development for the Treatment and Prevention of Urinary Tract Infections [Internet]. Vol. 4. 2016. 13-19 p. Available from: https://www.ncbi.nlm.nih.gov/pubmed/26999391

7. Lopez Mora, M. J., Yomayusa González, N., Montero Cetina, C., Torres Serrano, R., \& Ibañez Pinilla M. Incidencia, frecuencia, etiología y factores de riesgo para la infección en pacientes adultos con trasplante renal de un programa de trasplante de Bogotá. 2015; Available from: http://www.bdigital.unal.edu.co/49209/1/52965694. 2015.pdf

8. Garcia-Gomez M, Guio L, Hernandez JL, Vilar B, Pijoan JI, Montejo JM. Bacteraemia due to extended-spectrum beta-lactamases (ESBL) and other beta-lactamases (ampC and carbapenemase) producing Enterobacteriaceae: association with health-care and cancer]. Rev Esp Quim [Internet]. 2015;28(5):256-62. Available from: https://www.ncbi.nlm.nih.gov/pubmed/26437756

9. Bodro M, Sanclemente G, Lipperheide I, Allali M, Marco $\mathrm{F}$, Bosch J, et al. Impact of urinary tract infections on short-term kidney graft outcome. Clin Microbiol Infect [Internet]. 2015;21(12):1104.e1-1104.e8. Available from:

http://www.sciencedirect.com/science/article/pii/S11 98743X15007363

10. Calza MY, Badaracco ME, Aguerre MA, Maurich MS, Bangher MC, Peña L. Infección urinaria por enterobacterias multirresistentes en un centro de trasplante renal. Actual SIDA Infectol [Internet]. 2015;23(87):21-5. Available from: http://infectologia.info/revista/87/infeccion-urinariapor-enterobacterias-multirresistentes-en-un-centrode-trasplante-renal/

11. Enrique R, Abascal C, Ignacio S, Romero C, Pérez AH, Estrella M, et al. Experiencia en el tratamiento de la 
infección bacteriana en receptores de trasplante renal Experience in the treatment of bacterial infection in renal transplant recipients. 2016;55(1):6-19. Available from:

http://scielo.sld.cu/scielo.php?script=sci_arttext\&pid= S0034-75232016000100002

12. Requelme, S., Chávez, M., Natividad, E., Ramírez, R., Sauceda, E., \& Villanueva J. Identificación y evaluación de la susceptibilidad antimicrobiana de bacterias causantes de infección en pacientes con órganos trasplantados. Revista CIENCIA Y TECNOLOGÍA, 10(1), 151-165. 2014; Available from: http://revistas.unitru.edu.pe/index.php/PGM/article/ view/518

13. Lopez M, Ruiz JC, Arribas D, Calabria E, Alonso I. Inmunobiología del Trasplante. Estudios inmunológicos del donante y del receptor del trasplante renal. Inmunobiología Del Traspl [Internet]. 2017;6(6):3265. Available from: http://www.revistanefrologia.com/es-monografiasnefrologia-dia-articulo-inmunobiologia-del-trasplanteestudios-inmunologicos-del-donante-del-receptor-146

14. Valdivia Arencibia J. Factores de riesgo para la supervivencia en pacientes renales crónicos en hemodiálisis y transplante renal. e-libro [Internet]. 2012;61(610). Available from: http://www.sld.cu/galerias/pdf/sitios/cimeq/2008_tesis_doctoral-julio_valdivia.pdf

15. Perez MJ, Arcos EN, Comas M, Crespo J TJ. Trasplante Renal - Resultados y estudios epidemiológicos. 2016;49(5):129-36. Available from: http://scielo.isciii.es/pdf/nefrologia/v34s1/22_resum enes21.pdf

16. Cia CT, Li MJ, Li CW, Lee NY, Chang SS, Lee CC, et al. Community-onset bacteremia in kidney transplant recipients: The recipients fare well in terms of mortality and kidney injury. J Microbiol Immunol Infect [Internet]. Elsevier Taiwan LLC; 2016;49(5):685-91. Available http://dx.doi.org/10.1016/j.jmii.2014.08.027

17. Hernández PAA, López LCC, Anacona CAR. Calidad De Vida Y Estrategias De Afrontamiento En Pacientes Con Insuficiencia Renal Crónica Sometidos a Hemodiálisis, Diálisis Peritoneal Y Trasplante Renal. Rev Colomb Psicol [Internet]. 2009;17:9-26. Available from: http://www.revistas.unal.edu.co/index.php/psicologia /article/view/1233

18. Alberú J, Gómez-Navarro B, Medeiros M, Monteón F, Ponce-de-león A, Reyes-acevedo R, et al. Prevención de las infecciones en el receptor de trasplante renal: recomendaciones de un grupo de expertos. 2014;3:5665. Available from: http://www.medigraphic.com/cgi$\mathrm{bin} / \mathrm{new} /$ resumen.cgi?IDARTICULO $=52158$

19. Lee JR, Muthukumar T, Dadhania D, Taur Y, Jenq RR, Toussaint NC, et al. Gut microbiota and tacrolimus dosing in kidney transplantation. PLoS One [Internet]. 2015;10(3):1-17. Available from: https://journals.plos.org/plosone/article?id=10.1371/ journal.pone.0122399

20. R. R-S, D. D-O, R.R. F-P, E.E. G-J, R. E-H, A.A. B-B, et al. Prospective study of urinary tract infection surveillance after kidney transplantation. BMC Infect Dis [Internet]. 2010;10. Available from: http://www.biomedcentral.com/1471-

2334/10/245\%5Cnhttp://ovidsp.ovid.com/ovidweb.c gi?T $=$ JS $\& P A G E=$ reference $\& D=$ emed $9 \& N E W S=N \& A N=2$ 010512620

21. Lulichac SER, Castillo MC, Natividad EI, Ponce RAR, Amaya EAS, Villanueva JM. Identificación y evaluación de la susceptibilidad antimicrobiana de bacterias causantes de infección en pacientes con órganos trasplantados del hospital guillermo almenara. 2014;6781. Available from: http://revistas.unitru.edu.pe/index.php/PGM/article/ view/518

22. Mencarelli F, Marks SD. Non-viral infections in children after renal transplantation. Pediatr Nephrol [Internet]. 2012;27(9):1465-76. Available from: https://link.springer.com/article/10.1007/s00467011-2099-z

23. Gondos AS, Al-Moyed KA, Al-Robasi ABA, Al-Shamahy HA, Alyousefi NA. Urinary tract infection among renal transplant recipients in Yemen. PLoS One [Internet]. 2015;10(12):1-10. Available from: https://journals.plos.org/plosone/article?id=10.1371/ journal.pone.0144266

24. García-Prado ME, Cordero E, Cabello V, Pereira P, Torrubia FJ, Ruíz M, et al. Complicaciones infecciosas en 159 receptores de trasplante renal consecutivos. Enferm Infecc Microbiol Clin [Internet]. 2009;27(1):22-7. Available from: http://www.sciencedirect.com/science/article/pii/S02 13005X08000098

25. Kawecki D, Kwiatkowski A, Sawicka-Grzelak A, Durlik M, Mlynarczyk G, Chmura A. Bacterial and Fungal Infections in the Early Post-transplantation Period After Simultaneous Pancreas-kidney Transplantation: Etiological Agents and Their Susceptibility. Transplant Proc [Internet]. 2014;46(8):2802-5. Available from: http://www.sciencedirect.com/science/article/pii/S00 41134514007842

26. Ocharan-Corcuera J. Trasplante renal en España. Dial y Traspl. 2011;32(4):139-41.

27. Carvalho Brugger $S$, Gavilan Rabell R, Miralbes Torner M, Jimenez Jimenez G, Iglesias Moles S, Trujillano Cabello J, et al. Risk Factors for Colonization and Infection By Multiresistant Bacteria. Intensive Care Med Exp [Internet]. 2015;3(Suppl 1):A126. Available from: http://icmexperimental.springeropen.com/articles/10.1186/219 7-425X-3-S1-A126

28. 28.Smith J, Skeans M, Horslen S, Edwards E, Harper A SJ. Organ Procurement and Transplantation Network (OPTN) and Scientific Registry of Transplant Recipients (SRTR). OPTN/SRTR 2012 Annu Data Report [Internet]. 2014;14(1):97-111. Available from: https://optn.transplant.hrsa.gov

29. Rodrigue JR, Schold JD, Mandelbrot DA. The decline in living kidney donation in the United States: Random variation or cause for concern? Transplantation [Internet]. 2013;96(9):767-73. Available from: https://www.ncbi.nlm.nih.gov/pmc/articles/PMC3797 
198/

30. O. P. Organ procurement and transplantation network. ; 2015. Virginia HRSA, DHHS [Internet]. 2015; Available from: https://optn.transplant.hrsa.gov

31. Quilumbaquin F HA. Incidencia de Infección de vías urinarias IVU en pacientes con trasplante renal del área de nefrología del Hospital Carlos Andrade Marín en el periodo de Junio-Noviembre del 2014. 2014; Available from:

http://www.dspace.uce.edu.ec/handle/25000/7867

32. Colquechagua Aliaga F, Sevilla Andrade C, Gonzales Escalante E. Enterobacterias productoras de betalactamasas de espectro extendido en muestras fecales en el Instituto Nacional de Salud del Niño, Perú. Rev Peru Med Exp Salud Publica [Internet]. 2015;32(1):26-32. Available from: http://www.scielo.org.pe/scielo.php?pid=S172646342015000100005\&script=sci_abstract

33. Chacón PM, Viguria FB, Aniceto ÁA, Cervera C, Méndez $C$, Rodriguez $\mathrm{C}$, et al. Infección del tracto urinario en receptores de trasplante renal Urinary tract infection in renal transplant recipients. An Fac med [Internet]. 2017;2:11-6. Available from: http://www.scielo.org.pe/pdf/afm/v78n1/a02v78n1.p df

34. Tafur, José David, Julián Andrés Torres and MVV. Mecanismos de resistencia a los antibióticos en bacterias Gram negativas. J Shellfish Res [Internet]. 2011;12(3):39-48. Available from: http://www.sld.cu/galerias/pdf/sitios/apua-

cuba/mecanismos_de_resistencia_a_los_antibioticos_en _bacterias_gram_negativas.pdf

35. Prescott LM, Harley JP KD. Microbiología. 5a ed. Madrid McGraw Hill Interam. 2004;

36. Levy SB, Bonnie M. Antibacterial resistance worldwide: Causes, challenges and responses. Nat Med [Internet]. 2004;10(12S):S122-9. Available from: https://www.nature.com/articles/nm1145

37. Levy SB. The challenge of antibiotic resistance [see comments]. Sci Am [Internet]. 1998;278(3):46-53. Available from: http://www.ncbi.nlm.nih.gov/htbinpost $/$ Entrez/query?db=m\&form $=6 \& d o p t=r \& u i d=0009$ 487702

38. Cabrera CE, Gómez RF, Zúñiga AE. La resistencia de bacterias a antibióticos, antisépticos y desinfectantes una manifestación de los mecanismos de supervivencia y adaptación. Colombia Médica, abril-junio, año/vol. 38, número 002 Universidad del Valle. Colomb Med [Internet]. 2007;38(2):149-58. Available from: http://redalyc.uaemex.mx/redalyc/html/283/283382 08/28338208.html

39. Becerra G, Plascencia A, Luévanos A, Domínguez M, Hernández I. Mecanismo de resistencia a antimicrobianos en bacterias. Enfermedades Infecc y Microbiol [Internet]. 2009;29(2):70-6. Available from: http://www.medigraphic.com/pdfs/micro/ei2009/ei092e.pdf

40. Morosini MI, Cercenado E, Ardanuy C, Torres C. Detección fenotípica de mecanismos de resistencia en microorganismos grampositivos. Enferm Infecc Microbiol Clin [Internet]. 2012;30(6):325-32. Available from: $\quad$ http://www.elsevier.es/es-revistaenfermedades-infecciosas-microbiologia-clinica-28articulo-deteccion-fenotipica-mecanismos-resistenciamicroorganismos-S0213005X11003107

41. Lozano C, Torres C. Actualización en la resistencia antibiótica en Gram positivos. Enferm Infecc Microbiol Clin [Internet]. 2017;35:2-8. Available from: http://www.sciencedirect.com/science/article/pii/S02 13005X17300289

42. Espinar MJ, Miranda IM, Costa-De-Oliveira S, Rocha R, Rodrigues AG, Pina-Vaz C. Urinary tract infections in kidney transplant patients due to Escherichia coli and Klebsiella pneumoniae-producing extended-spectrum $\beta$-lactamases: Risk factors and molecular epidemiology. PLoS One [Internet]. 2015;10(8):1-11. Available from: https://journals.plos.org/plosone/article/file?id=10.13 71/journal.pone.0134737\&type=printable

43. Velandia DPL, Torres Caycedo MI, Castañeda Orduz LM, Prada Quiroga CF. Determinación de genes que codifican la resistencia de betalactamasas de espectro extendido en bacilos Gram negativos aislados de urocultivos. Rev Investig en Salud Univ Boyacá [Internet]. 2016;3(2):107. Available from: http://revistasdigitales.uniboyaca.edu.co/index.php/rs /article/view/182

44. Samanipour A, Dashti-Khavidaki S, Abbasi M-R, Abdollahi A. Antibiotic resistance patterns of microorganisms isolated from nephrology and kidney transplant wards of a referral academic hospital. J Res Pharm Pract [Internet]. 2016;5(1):43. Available from: http://www.jrpp.net/text.asp?2016/5/1/43/176559

45. Adeyemi OA, Qi C, Zembower TR, Ison MG, Grant TH, Hartigan BJ, et al. Invasive infections with communityassociated methicillin-resistant Staphylococcus aureus after kidney transplantation. J Clin Microbiol [Internet]. 2008;46(8):2809-13. Available from: https://jcm.asm.org/content/46/8/2809

46. Julio D, Medina C, Antelo V, Nin M, Arteta Z, González F, et al. Infecciones bacterianas en pacientes receptores de trasplante renal y reno-páncreas : alta incidencia de microorganismos multirresistentes. 2012;28(3):190-8. Available http://www.rmu.org.uy/revista/2012v3/art5.pdf

47. Pouladfar G, Jafarpour Z, Hosseini SAM, Janghorban P, Roozbeh J. Antibiotic Selective Pressure and Development of Bacterial Resistance Detected in Bacteriuria Following Kidney Transplantation. Transplant Proc [Internet]. 2015;47(4):1131-5. Available

from: http://www.sciencedirect.com/science/article/pii/S00 41134515002031

48. Henríquez Iguarán DE, Rivera Vargas SM, Leal Castro AL, Díaz Ortega $\mathrm{MH}$, Robledo Restrepo CG, Villegas Botero MV, et al. Tendencias de los fenotipos de resistencia bacteriana en hospitales públicos y privados de alta complejidad de Colombia. Rev Panam Salud Pública [Internet]. 2011;30(6):627-33. Available from:

http://www.grupogermen.org/pdf/ins_germen2011.p df

49. Montúfar-Andrade FE, Mesa-Navas M, Aguilar-Londoño 
C, Saldarriaga-Acevedo C, Quiroga-Echeverr A, BuilesMontaño CE, et al. Experiencia clínica con infecciones causadas por Klebsiella pneumoniae productora de carbapenemasa, en una institución de enseñanza universitaria en Medellín, Colombia. Infectio [Internet]. 2016;20(1):17-24. Available from: http://www.sciencedirect.com/science/article/pii/S01 23939215000831

50. Ferreira FE, Olaya SX, Zúñiga $P$, Angulo M. Urinary infection during pregnancy: a profile of resistance to treatment in the General Hospital in Neiva, Colombia. Rev Colomb Obstet Ginecol [Internet]. 2005;56(3):23943. Available

from: http://www.redalyc.org/articulo.oa?id=19521431100 7

51. Coccia P, Blazquez J, Contreras M, Raddavero C, Ghezzi L, Busaniche J, et al. Alta prevalencia de deficiencia de vitamina D en niños con enfermedad renal crónica y trasplante renal. 2017;115(3):220-6. Available from: http://www.scielo.org.ar/scielo.php?script=sci_abstrac t\&pid=S0325-00752017000300003

52. Park Y-J, Kwon E, Jung H-Y, Kim S-H, Seo M-Y, Lee S, et al. Vitamin d deficiency is associated with increased bacterial infections after kidney transplantation. Transpl Int [Internet]. 2015;28:358-9. Available from: http://www.embase.com/search/results?subaction=vi ewrecord\&from=export\&id=L72112124\%5Cnhttp://d x.doi.org/10.1111/tri.12702\%5Cnhttp://sfx.library.uu. nl/utrecht?sid=EMBASE\&issn=09340874\&id=doi:10.1 111\%2Ftri.12702\&atitle=Vitamin $+d+$ deficiency+is+ass ociated+with+incr 